\title{
Roles of oncogenes and tumor-suppressor genes in osteoclastogenesis (Review)
}

\author{
AKARI MINAMI $^{*}$, MAKO OGINO ${ }^{1 *}$, NORIKO NAKANO ${ }^{1}$, MAYUKO ICHIMURA $^{1}$, ATSUKO NAKANISHI $^{2}$, \\ TOSHIYUKI MURAI $^{3,4}$, YASUKO KITAGISHI ${ }^{{ }^{*}}$ and SATORU MATSUDA ${ }^{1 *}$ \\ ${ }^{1}$ Department of Food Science and Nutrition, Nara Women's University, Kita-Uoya Nishimachi, Nara 630-8506; \\ ${ }^{2}$ Department of Food and Nutrition, Faculty of Contemporary Human Life Science, Tezukayama University, \\ Nara 631-8501; Departments of ${ }^{3}$ Microbiology and Immunology, and ${ }^{4}$ Genome Biology, \\ Graduate School of Medicine, Osaka University, Suita 565-0871, Japan
}

Received October 17, 2016; Accepted December 28, 2016

DOI: $10.3892 /$ ijmm.2017.2847

\begin{abstract}
Osteoporosis is a bone disease that poses a tremendous burden to health care. The receptor activator of nuclear factor- $\kappa \mathrm{B}(\mathrm{RANK})$ and its ligand (RANKL) have been a major focus of this research field. RANKL signaling not only activates a variety of downstream signaling pathways required for osteoclast development, but crosstalk with other signaling pathways also adjusts bone homeostasis both in normal physiology and in bone disease. Consequently, novel drugs specifically targeting RANK-RANKL and their signaling pathways in osteoclasts are expected to revolutionize the treatment of various bone diseases such as osteoporosis. Osteoclasts are the exclusive cells involved in bone resorption. Abnormal activation of osteoclasts can lead to reduced bone density, resulting in osteopenia, osteoporosis and other bone disorders. To date, the mechanism of how osteoclast precursors differentiate into mature osteoclasts remains elusive. Cell proliferation and cell death may be key processes in the
\end{abstract}

Correspondence to: Professor Satoru Matsuda, Department of Food Science and Nutrition, Nara Women's University, Kita-Uoya Nishimachi, Nara 630-8506, Japan

E-mail: smatsuda@cc.nara-wu.ac.jp

*Contributed equally

Abbreviations: BMP, bone morphogenetic proteins; CDK, cyclindependent kinase; CSF1, colony-stimulating factor 1; DHA, docosahexaenoic acid; GSK-3 $\beta$, glycogen synthase kinase-3 $\beta$; MAPK, mitogen-activated protein kinase; n-3 PUFA, $\omega-3$ polyunsaturated fatty acid; NAD, nicotinamide adenine dinucleotide; NFATc1, nuclear factor of activated T cells 1; PI3K, phosphoinositide 3-kinase; PTEN, phosphatase and tensin homolog on chromosome 10; PUFAs, polyunsaturated fatty acids; RANK, receptor activator of nuclear factor- $\kappa \mathrm{B}$; RANKL, RANK ligand; RNAi, RNA interference; ROS, reactive oxygen species; TGF, transforming growth factor

Key words: osteoporosis, osteoclasts, Src, Myc, TP53, phosphatase and tensin homolog progression as well as other cell types. Oncogene products and tumor-suppressor molecules play a pivotal role in regulating the processes, which are important in regulating the configuration of bone disorders. Based on the understanding of these processes, promising alternatives to the use of medications against osteoporosis include specific diets with plant-derived supplements to modulate the expression and/or activity of these molecules. In this review, we summarize the progress of research with a focus on the modulatory roles of oncogene products and tumor-suppressor molecules and suggest the scope of further research concerning the prevention of osteoporosis in this field.

\section{Contents}

1. Introduction

2. Oncogenes are involved in osteoclastogenesis

3. Tumor-suppressor genes are involved in osteoclastogenesis

4. Strategy for the dietary treatment of osteoporosis

5. Future perspectives

\section{Introduction}

Bone fracture is a health issue in patients with bone-related disorders such as osteoporosis as it is a common event (1). Healthy bone homeostasis depends on a balance between osteoblastic bone formation and osteoclastic bone resorption (2) (Fig. 1). Bone remodeling also requires a balance in growth, differentiation, and activity of osteoblasts and osteoclasts. Multinucleated osteoclasts resorb lamellar bone, and new bone is generated by osteoblasts. An imbalance can lead to impaired bone structure and/or small bone mass. Accordingly, osteoclasts are functionally indispensable for supporting bone health. Hyperactivation of osteoclasts and/or their increased number can lead to diseases characterized by bone loss, which is a key risk factor for bone fracture (3). Bone resorption leads to degradation of extracellular matrix which alters the environment of bone marrow stem cell binding and differentiation. On the other hand, bone morphogenetic proteins (BMPs), which 


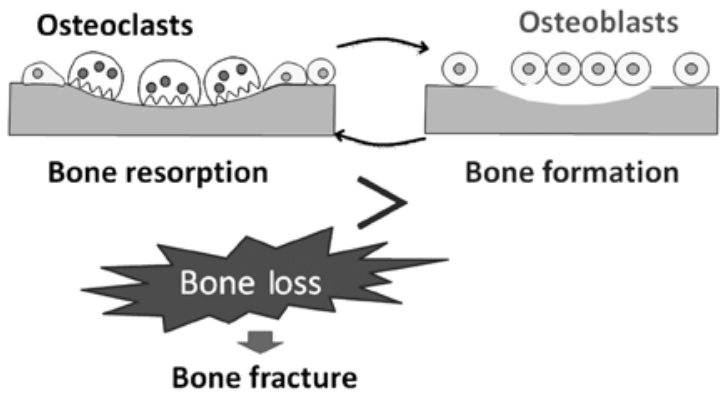

Figure 1. Schematic representation of bone homeostasis that depends on a balance between osteoblastic bone formation and osteoclastic bone resorption.

are members of the transforming growth factor (TGF)- $\beta$ superfamily and in charge of the development and function of different cell types, induce bone formation (4). It has been shown that BMP signaling in osteoblasts regulates bone mass in mice, suggesting a role of BMP in osteoclastogenesis along with osteoblastic action (5). In addition, postmenopausal osteoporotic bone loss may largely result from the stimulation of bone resorption via increased osteoclast formation with insufficient osteoblastic bone formation (6). Clinically, medical orally available bisphosphonates targeting osteoclasts have been widely used to treat patients with osteoporosis and/ or prevent osteoporotic fracture. Bisphosphonates principally inhibit the activation of osteoclasts by binding to hydroxyapatite (7); however, bisphosphonate-related side effects including hypocalcaemia, secondary hyperparathyroidism, renal toxicity, gastrointestinal tract problems and osteonecrosis have recently been reported (8). Colony-stimulating factor 1 (CSF1) is a growth factor required for the differentiation of monocyte-macrophage precursor cells into preosteoclasts (9). Osteoblasts produce CSF1 and receptor activator of nuclear factor- $\kappa \mathrm{B}$ ligand (RANKL) which is essential for the early development of osteoclasts from precursor cells derived from monocyte/macrophage lineage originating from the liver and spleen (10). Membrane-bound RANKL invites osteoclasts and initiates and/or activates their differentiation to form multinucleated cells. The role of BMPs in osteoclast differentiation has also been demonstrated, which induce RANKL expression in osteoblasts. CSF1 is controlled by a Smad-signaling pathway (11). In addition, the involvement of the phosphatidylinositol 3-kinase (PI3K) and AKT signaling pathways has been shown to be critical both in osteoblast and in osteoclast differentiation in response to BMPs (11). Consequently, BMPs induce secretion of CSF1 dependent on PI3K/AKT signaling. Inhibition of PI3K/AKT signaling blocks the binding of Smads to the CSF1 BMP-responsive element present in the CSF1 promoter, resulting in attenuation of Smad-dependent CSF1 transcription (12).

Proto-oncogenes and tumor-suppressor genes, which are important in the normal development of cells, are involved in the regulation of the cell cycle and apoptosis (13). For example, the proto-oncogene $c$-Src has been implicated in the development and mature function of the nervous system (14). The protein product of the $c$-Src gene is a tyrosine protein kinase that is enriched in fetal neural tissues. Nuclear transcription of $c$-Src and other proto-oncogenes such as N-ras, $c-M y c$ and
$c$-Fos have been observed in proliferating and differentiating cells (15). In general, oncogenes are critically positioned in various growth factor receptor signaling pathways and are relevant in cancer development (16). TP53 is a well-known tumor-related gene expressed ubiquitously in all cell types as an inactive transcription factor which undertakes activation in response to a variety of cellular stresses. TP53 acts both as an oncogene and a tumor-suppressor gene. The effects of TP53 are mediated by different downstream effectors and target proteins. Among them, cyclin-dependent kinase (CDK) inhibitors such as p21 are key mediators of TP53 action, in which p21 may be involved in cell differentiation (17). In addition, p21 regulates cell cycle progression, cell differentiation and senescence (18). Phosphatase and tensin homolog (PTEN) is also a well-known tumor-suppressor gene product of the pten gene. PTEN is a dual-specificity phosphatase that has been shown to prevent cell proliferation and migration $(19,20)$. The PTEN/AKT pathway appears to be important in the regulation of inflammatory responses (21).

\section{Oncogenes are involved in osteoclastogenesis}

Osteoclasts are multinucleated cells that are formed by the fusion of mononuclear osteoclasts, which is an essential process in bone resorption leading to bone remodeling (22). Mechanical response is known to regulate bone remodeling, yet the molecular events involved in the mechanical signal transduction are poorly understood. However, RANKL may be the most essential cytokine involved in the genesis of osteoclasts and/or osteoclast differentiation (23). The binding of RANKL to RANK provokes activation of signaling molecules including AKT and ERK that later induce the activation of transcription factors such as nuclear factor of activated T cells (NFATc1) and c-Fos to regulate the expression of genes required for osteoclast differentiation $(24,25)$. The expression of c-Fos and NFATc1 is regulated by the ERK signaling pathway (26). Proto-oncogene product c-Fos is an essential factor for the induction of NFATc1, which is a master transcription factor that regulates the process of osteoclast differentiation by controlling osteoclast-specific genes $(27,28)$. NFATc1 plays a role as a transcription factor required for regulating the expression of osteoclast-specific genes including TRAP and c-Src (29). c-Src tyrosine kinase (Fig. 2) is also required for the maintenance of osteoclasts and control of bone resorption through actin cytoskeleton turnover $(30,31)$. Selective c-Src inhibitors induce osteoclast disruption and consequently reduce osteoclast numbers in vivo, which induce programmed cell death in mature osteoclasts $(32,33)$. Caspase-3 and -9 are momentarily activated by treatment with c-Src inhibitors probably involving continual ERK1/2 phosphorylation (34). Both $c$-Fos and $c$-Src are proto-oncogenes. In addition, proto-oncogene $c-M y c$ is strongly upregulated in RANKLinduced osteoclasts (Fig. 2), and is a transcription factor expressed at comparatively high levels in preosteoclasts (35). Consistent with this, a dominant-negative Myc could block RANKL-induced osteoclast formation (35). TRAP, a typical marker of osteoclast differentiation, is an enzyme that plays an active role in the process of bone resorption. The specific regulation of TRAP is performed at the transcriptional level by Myc, suggesting that Myc may play an active role in 

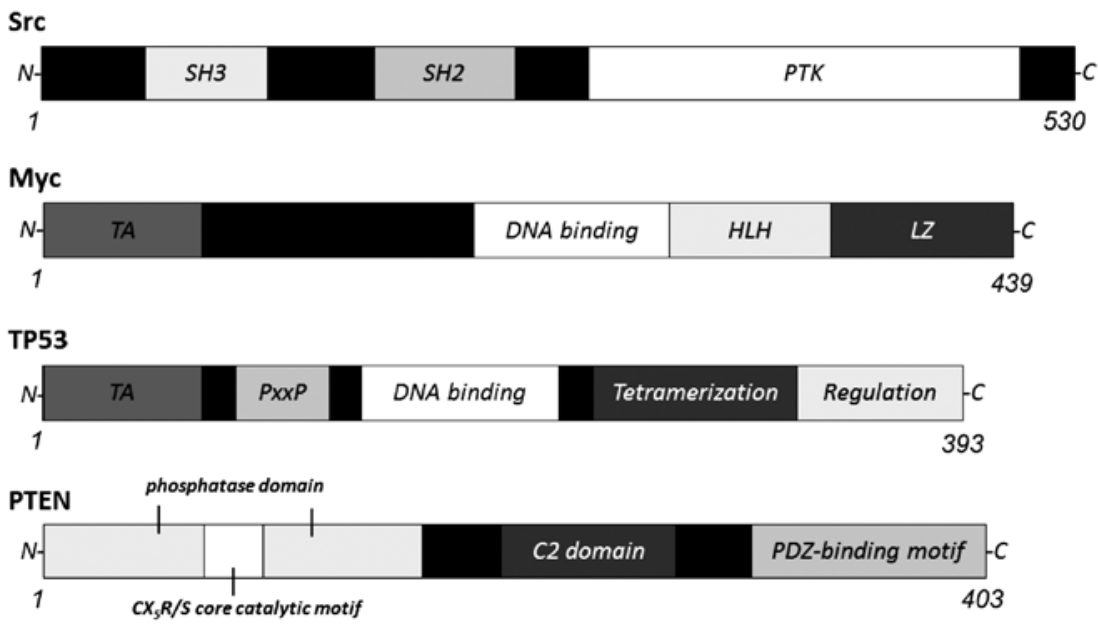

Figure 2. Schematic structures of Src, Myc, TP53 and PTEN protein. The predicted consensual domain structures for each protein are depicted. The functionally important sites are also shown. Note that the sizes of the protein are modified for clarity. SH3, Src homology 3 domain; SH2, Src homology 2 domain; PTK, protein tyrosine kinase domain; TA, transactivation domain; HLH, helix-loop-helix domain; LZ, leucine zipper domain; PxxP, proline-rich region; C2 domain, a protein structural domain involved in targeting proteins to cell membranes; PDZ, a common structural domain in signaling proteins (PSD95, Dlg and ZO-1).

suppressing the transcription of mature osteoclast genes (36). In addition, Myc has a function in the stimulation of FOXO1 which plays key roles in bone development and remodeling by stimulating osteoclast formation (37). In addition to PI3K/ AKT signaling, small Ras GTPase also regulates osteoclast survival. Increased activity of Ras GTPase induces the binding with PI3K, whereas inhibition of Ras reduces PI3K-mediated osteoclast survival (38). Actually, the pharmacological inhibition of H-ras prevents the downstream mechanical repression of RANKL (39). Consistently, RNA interference (RNAi) of $H$-ras also retracts the mechanical repression of RANKL (39), suggesting that the mechanical repression of RANKL requires a specific form of Ras-GTP activity. Spatial arrangements in the lipid raft microdomain may be critical for downstream events in response to mechanical signals. In general, activation of Ras and the mitogen-activated protein kinase (MAPK) signaling pathway is known to underlie the proliferation and differentiation of different types of cell lineages including osteoclast progenitor cells (40).

\section{Tumor-suppressor genes are involved in osteoclasto- genesis}

Treatment with RANKL was found to induce an accumulation of TP53 protein in a dose-dependent manner, consequently activating TP53 target genes (41). TP53 is a known tumorsuppressor molecule and also regulates osteoclastdifferentiation (Fig. 2). Mice with deficiency of the TP53 gene display a high bone-mass phenotype (42). In addition, TP53-deficient mice have an improved ability to prefer osteoclast differentiation with increased expression of CSF1 $(42,43)$. Therefore, TP53 acts as a regulator of osteoclastogenesis and subsequent bone remodeling $(42,43)$. Bone loss induced by ovariectomy has been linked to enhanced bone turnover as a result of osteoclast activation (44), accompanied by increased expression of the senescence marker p16/p21 in bone associated with a decrease in Sirt1 (44). In general, bone cell senescence is associated with decreased Sirt1 expression and activation of TP53, p16 and p21 (45). Sirt1 is a candidate anti-aging gene which may suppress p16 expression through deacetylation (45). Although the TP53 and p16 pathways act separately to promote cellular senescence, their contribution can be cell type-dependent depending on the process (46). Cellular senescence is a process of aging involving a permanent growth arrest of mitotic cells and is different from apoptosis and/or programmed cell death.

PTEN (Fig. 2) is a frequently mutated tumor-suppressor gene in human cancers (47). PTEN has been found to regulate cell survival, growth, migration, adhesion, and invasiveness (48). PTEN adversely regulates PI3K/AKT signaling as a lipid phosphatase for the phosphatidylinositol 3,4,5-triphosphate second messenger. Inactivation of glycogen synthase kinase-3 $\beta$ (GSK-3 $\beta$ ) via AKT plays an important role in RANKL-induced osteoclastogenesis (49). Downregulation of PTEN by RNAi increases AKT and GSK-3 $\beta$ phosphorylation by RANKL, thereby stimulating the development of osteoclasts (50). Notably, the phosphorylation defective mutant of PTEN at threonine 366 was found to result in increased osteoclastgenesis compared to that of wild-type PTEN. PTEN phosphorylation seems to reduce RANKL-induced osteoclastogenesis, whereas PTEN protein levels are unaffected (50). Treatment with GSK-3 $\beta$ inhibitor SB216763 was found to dose-dependently suppress PTEN phosphorylation consequently increasing AKT phosphorylation. RANKL stimulates activation of AKT, which in turn is consistent with the role of an increased level of PTEN in decreasing AKT activity. These data strongly suggest that inhibition of GSK-3 $\beta$ during RANKL-induced osteoclastogenesis decreases PTEN phosphorylation, contributing to osteoclast differentiation through subsequent AKT activation. PTEN overexpression also blocks RANKL-triggered AKT activation that is related to cell survival and cell migration. Thus, PTEN overexpression suppresses RANKL-mediated osteoclast differentiation. On the contrary, the dominant-negative form of PTEN induces osteoclast differentiation and migration. In this way, multiple roles for PTEN have been shown in RANKL-induced osteoclast precursor cells $(50,51)$. 


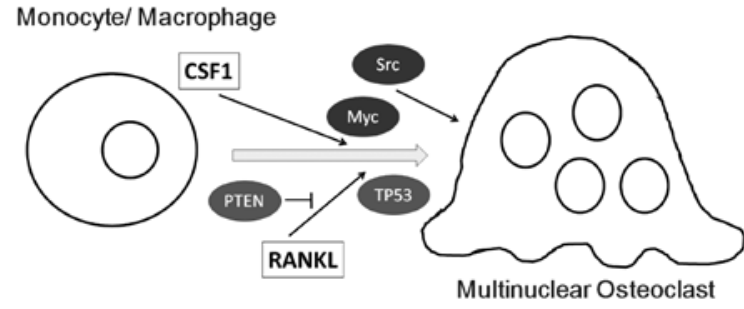

Figure 3. Schematic illustration of the tentative proposed model for osteoclastogenesis mediated by oncogenes and tumor-suppressor genes in addition to the stimulation of colony-stimulating factor 1 (CSF1) and receptor activator of nuclear factor- $\kappa \mathrm{B}$ ligand (RANKL). Examples of molecules involved in osteoclastogenesis are shown. Note that some critical pathways have been omitted for clarity.

\section{Strategy for the dietary treatment of osteoporosis}

Potential therapeutic strategies exploit the observations made in the critical processes required for maintaining homeostasis of the metabolic condition characterized by osteoblast/ osteoclast balance. Accordingly, dietary regulation of these cells is an important therapeutic strategy for preventing and/or treating bone disorders. As mentioned above, several oncogenes and tumor-suppressor genes are intensely involved in osteoclastogenesis and/or osteoporosis. Thus, it is a challenge to regulate the expression of these genes by dietary treatment. First of all, inhibition of oncogene expression such as c-Myc and $c-H$-ras by green tea and (-)-epigallocatechin gallate has been shown in mice (52). In addition, antioxidants such as retinoids (vitamin A), vitamin E (such as $\alpha$-tocopheryl succinate), ascorbate (vitamin C) and carotenoids induce cell differentiation and growth inhibition in human cells by complex mechanisms including inhibition of the expression of c-Myc and $\mathrm{H}$-ras and induction of p21 genes (53). Moreover, dietary calorie restriction has been associated with reduced cancer risk, which is related to the abrogation of both Ras and PI3K signaling (54).

Praeruptorin A is the major bioactive component isolated from the dry root extract of Peucedanum praeruptorum Dunn, and has several biological activities such as anti-hypertensive activity by acting as a calcium channel blocker (55). Praeruptorin A attenuates the RANKL-induced phosphorylation of p38 without affecting JNK and ERK activity. The anti-osteoclastogenic action of praeruptorin A may be due to its potential to inhibit both the p38 and AKT signaling pathways that subsequently downregulate the expression of c-Fos and NFATc1 (56). Honokiol, a component of the Oriental herb Magnolia officinalis, inhibits RANKL-induced osteoclastogenesis with nuclear factor- $\kappa \mathrm{B}(\mathrm{NF}-\kappa \mathrm{B})$ activation (57). Studies have shown that honokiol blocks TNF-induced phosphorylation, degradation and ubiquitination of $\mathrm{I} \kappa \mathrm{B} \alpha$ through the inhibition of AKT (58). Expression of c-Myc is also downregulated by honokiol (59). Honokiol can diminish PI3K/AKT signaling by upregulation of PTEN expression (60). Magnolol, a honokiol isomer, has been shown to be equally active. Consumption of a blueberry-containing diet may contribute to the prevention of bone loss (61). Blueberries are an admirable source of dietary polyphenols such as phenolic acids and anthocyanins, which were found to significantly decrease the gene expression of TP53 and p21 in human
HepG2 cells (62). Resveratrol was also found to activate Sirt1, a member of the sirtuin family of nicotinamide adenine dinucleotide (NAD)-dependent deacetylases (63). Stilbenes, which are related to resveratrol, have been shown to have an inhibitory effect on the expression of the c-Myc genes (64). In addition, resveratrol inhibits cell proliferation and induces cell apoptosis through regulation of TP53 expression (65). An extract from thorns of the medicinal herb, Gleditsia sinensis caused an increase in cell cycle arrest during the G2/M phase, associated with increased TP53 levels (66). Treatment with an ethanol extract of the thorns of Gleditsia sinensis was also found to be associated with upregulation of p21 levels (67). Both TP53 and p21 mRNA levels were increased following treatment with the Chinese herb Kanglaite, an extract from Coix seed (68). Kanglaite appears to extend the half-life of TP53 protein (68). A ginsenoside, one of the components of American ginseng herb, was found to activate TP53 (69). In addition, apoptosis induction by thymoquinone, the most abundant component in black seed, was found to be associated with an increase in TP53 mRNA and downstream TP53 target genes (70,71). Treatment with an extract of Magnolia officinalis upregulated the expression of p21 and p27 (72). Baicalin, a herb-derived flavonoid compound, enhanced the expression of p27 $(73,74)$. Treatment with an extract of Saussurea involucrate was also found to induce p21 and p27 expression, independent of the TP53 pathway (75). Treatment with triptolide, a purified extract from the herb Tripterygium wilfordii Hook F resulted in increased p21 expression (76,77). Curcumin, an active ingredient derived from the root of the plant Curcuma longa, restored PTEN expression (78). In contrast, various components of the herb rosemary inhibited the expression of PTEN in K562 myeloid cells (79).

Dietary intake of indole-3-carbinol was found to upregulate PTEN in an animal model (80). Indole-3-carbinol is a promising cancer-preventive phytochemical found in various vegetables such as broccoli (81). In addition, PTEN expression at the mRNA and protein levels was found to be elevated in experimental animals fed whey protein which has been shown to possess multiple health benefits (82). It has also been reported that DHA and EPA raise the level of PTEN in breast cancer cells, providing a mechanism for the beneficial effects of fish oils on breast cancer cells $(83,84)$. Fish oil rich in polyunsaturated fatty acids may induce PTEN expression by activation of peroxisome proliferator-activated receptor (PPAR) $(85,86)$, which attenuates cellular damage playing an important role in the activation of anti-apoptotic signaling (87). The information discussed here may also be useful for supporting the design of further research concerning the prevention of osteoporosis.

\section{Future perspectives}

It will be a challenge to elucidate how to utilize natural compounds for the correction of critical processes required for maintaining cellular homeostasis and metabolic conditions to prevent osteoporosis (Fig. 3). Identification of effective target molecules relevant for osteoporosis allows the screening for natural products capable of modulating targets. In addition, combination therapy using two or more food ingredients is a promising therapeutic strategy over traditional approaches. For example, resveratrol and curcumin synergistically induce 
apoptosis by increasing the level of p21 and decreasing the level of c-Myc (88). The information here may provide further insight into the molecular mechanisms of special diets underlying the daily use of certain foods as a therapeutic strategy for osteoporosis. This may also provide the basis for the development of rational dietary treatments against other diseases. Future studies are required to demonstrate whether oncogenes, tumor-suppressor genes and/or their downstream targets could be used to modulate the cellular composition of tissue including bone, thereby enhancing metabolic stability. Knowledge of the local determinants of the phenotype of osteoclasts in critical lesions and how they interact with the risk factors of bone disorders may lead to significantly improved therapies with reduced side effects.

\section{Acknowledgements}

This review was supported by JSPS KAKENHI (grant nos. 26-12035 and 24240098).

\section{References}

1. Ward LM, Konji VN and Ma J: The management of osteoporosis in children. Osteoporos Int 27: 2147-2179, 2016.

2. Pi C, Li YP, Zhou X and Gao B: The expression and function of microRNAs in bone homeostasis. Front Biosci (Landmark Ed) 20 119-138, 2015.

3. Horwood NJ: Macrophage polarization and bone formation: a review. Clin Rev Allergy Immunol 51: 79-86, 2016.

4. Sartori R and Sandri M: BMPs and the muscle-bone connection. Bone 80: 37-42, 2015

5. Paul S, Lee JC and Yeh LC: A comparative study on BMP-induced osteoclastogenesis and osteoblastogenesis in primary cultures of adult rat bone marrow cells. Growth Factors 27: 121-131, 2009.

6. Riggs BL, Khosla S and Melton LJ III: Sex steroids and the construction and conservation of the adult skeleton. Endocr Rev 23: 279-302, 2002.

7. Murphy CM, Schindeler A, Gleeson JP, Yu NY, Cantrill LC, Mikulec K, Peacock L, O'Brien FJ and Little DG: A collagen-hydroxyapatite scaffold allows for binding and co-delivery of recombinant bone morphogenetic proteins and bisphosphonates. Acta Biomater 10: 2250-2258, 2014.

8. Papapetrou PD: Bisphosphonate-associated adverse events. Hormones (Athens) 8: 96-110, 2009.

9. Mandal CC, Ghosh-Choudhury G and Ghosh-Choudhury N: Phosphatidylinositol 3 kinase/Akt signal relay cooperates with Smad in bone morphogenetic protein-2-induced colony stimulating factor-1 (CSF-1) expression and osteoclast differentiation. Endocrinology 150: 4989-4998, 2009.

10. Lampiasi N, Russo R and Zito F: The alternative faces of macrophage generate osteoclasts. BioMed Res Int 2016 9089610, 2016.

11. Mandal CC, Das F, Ganapathy S, Harris SE, Choudhury GG and Ghosh-Choudhury N: Bone morphogenetic protein-2 (BMP-2) activates NFATc1 transcription factor via an autoregulatory loop involving Smad/Akt/Ca ${ }^{2+}$ signaling. J Biol Chem 291: $1148-1161,2016$

12. Li W, Liu Z, Zhao C and Zhai L: Binding of MMP-9-degraded fibronectin to $\beta 6$ integrin promotes invasion via the FAK-Src-related Erk1/2 and PI3K/Akt/Smad-1/5/8 pathways in breast cancer. Oncol Rep 34: 1345-1352, 2015.

13. Aguirre E, Renner O, Narlik-Grassow M and Blanco-Aparicio C: Genetic modeling of PIM proteins in cancer: proviral tagging and cooperation with oncogenes, tumor suppressor genes, and carcinogens. Front Oncol 4: 109, 2014.

14. Yu XM and Salter MW: Src, a molecular switch governing gain control of synaptic transmission mediated by $N$-methyl-D-aspartate receptors. Proc Natl Acad Sci USA 96: 7697-7704, 1999.

15. Ingraham CA, Cox ME, Ward DC, Fults DW and Maness PF: c-Src and other proto-oncogenes implicated in neuronal differentiation. Mol Chem Neuropathol 10: 1-14, 1989.

16. Reichmann E: Oncogenes and epithelial cell transformation. Semin Cancer Biol 5: 157-165, 1994.
17. Kramer JL, Baltathakis I, Alcantara OS and Boldt DH: Differentiation of functional dendritic cells and macrophages from human peripheral blood monocyte precursors is dependent on expression of p21 (WAF1/CIP1) and requires iron. Br J Haematol 117: 727-734, 2002.

18. Grabliauskaite K, Hehl AB, Seleznik GM, Saponara E, Schlesinger K, Zuellig RA, Dittmann A, Bain M, Reding T, Sonda S, et al: p21 ${ }^{\text {WAF1/Cipl }}$ limits senescence and acinar-to-ductal metaplasia formation during pancreatitis. J Pathol 235: 502-514, 2015.

19. Nakanishi A, Wada Y, Kitagishi Y and Matsuda S: Link between PI3K/AKT/PTEN pathway and NOX proteinin diseases. Aging Dis 5: 203-211, 2014.

20. Matsuda S, Nakanishi A, Minami A, Wada Y and Kitagishi Y: Functions and characteristics of PINK1 and Parkin in cancer. Front Biosci (Landmark Ed) 20: 491-501, 2015.

21. Günzl P and Schabbauer G: Recent advances in the genetic analysis of PTEN and PI3K innate immune properties. Immunobiology 213: 759-765, 2008.

22. Appelman-Dijkstra NM and Papapoulos SE: Modulating bone resorption and bone formation in opposite directions in the treatment of postmenopausal osteoporosis. Drugs 75: 1049-1058, 2015

23. An J, Yang H, Zhang Q, Liu C, Zhao J, Zhang L and Chen B: Natural products for treatment of osteoporosis: the effects and mechanisms on promoting osteoblast-mediated bone formation. Life Sci 147: 46-58, 2016.

24. Wagner EF and Eferl R: Fos/AP-1 proteins in bone and the immune system. Immunol Rev 208: 126-140, 2005.

25. Asagiri $\mathrm{M}$ and Takayanagi $\mathrm{H}$ : The molecular understanding of osteoclast differentiation. Bone 40: 251-264, 2007.

26. Lee MS, Kim HS, Yeon JT, Choi SW, Chun CH, Kwak HB and Oh J: GM-CSF regulates fusion of mononuclear osteoclasts into bone-resorbing osteoclasts by activating the Ras/ERK pathway. J Immunol 183: 3390-3399, 2009.

27. Takayanagi H: The role of NFAT in osteoclast formation. Ann NY Acad Sci 1116: 227-237, 2007.

28. Macián F, López-Rodríguez C and Rao A: Partners in transcription: NFAT and AP-1. Oncogene 20: 2476-2489, 2001.

29. Zeng XZ, He LG, Wang S, Wang K, Zhang YY, Tao L, Li XJ and Liu SW: Aconine inhibits RANKL-induced osteoclast differentiation in RAW264.7 cells by suppressing NF- $\kappa$ B and NFATc1 activation and DC-STAMP expression. Acta Pharmacol Sin 37: 255-263, 2016.

30. Lee EJ, Kim JL, Gong JH, Park SH and Kang YH: Inhibition of osteoclast activation by phloretin through disturbing $\alpha \mathrm{v} \beta 3$ integrin-c-Src pathway. Biomed Res Int 2015: 680145, 2015.

31. Fukunaga T, Zou W, Warren JT and Teitelbaum SL: Vinculin regulates osteoclast function.J Biol Chem 289: 13554-13564, 2014

32. Shakespeare W, Yang M, Bohacek R, Cerasoli F, Stebbins K, Sundaramoorthi R, Azimioara M, Vu C, Pradeepan S, Metcalf C III, et al: Structure-based design of an osteoclast-selective, nonpeptide src homology 2 inhibitor with in vivo antiresorptive activity. Proc Natl Acad Sci USA 97: 9373-9378, 2000.

33. Rucci N, Ricevuto E, Ficorella C, Longo M, Perez M, Di Giacinto C, Funari A, Teti A and Migliaccio S: In vivo bone metastases, osteoclastogenic ability, and phenotypic characterization of human breast cancer cells. Bone 34: 697-709, 2004

34. Recchia I, Rucci N, Funari A, Migliaccio S, Taranta A, Longo M, Kneissel M, Susa M, Fabbro D and Teti A: Reduction of c-Src activity by substituted 5,7-diphenyl-pyrrolo[2,3-d]-pyrimidines induces osteoclast apoptosis in vivo and in vitro. Involvement of ERK1/2 pathway. Bone 34: 65-79, 2004

35. Battaglino R, Kim D, Fu J, Vaage B, Fu XY and Stashenko P: $\mathrm{c}-\mathrm{Myc}$ is required for osteoclast differentiation. $\mathrm{J}$ Bone Miner Res 17: 763-773, 2002.

36. Daumer KM, Taparowsky EJ, Hall DJ and Steinbeck MJ: Transcription from the tartrate-resistant acid phosphatase promoter is negatively regulated by the Myc oncoprotein. J Bone Miner Res 17: 1701-1709, 2002.

37. Wilhelm K, Happel K, Eelen G, Schoors S, Oellerich MF, Lim R, Zimmermann B, Aspalter IM, Franco CA, Boettger T, et al: FOXO1 couples metabolic activity and growth state in the vascular endothelium. Nature 529: 216-220, 2016.

38. Adapala NS, Barbe MF, Tsygankov AY, Lorenzo JA and Sanjay A: Loss of Cbl-PI3K interaction enhances osteoclast survival due to $\mathrm{p} 21$-Ras mediated PI3K activation independent of Cbl-b. J Cell Biochem 115: 1277-1289, 2014. 
39. Rubin J, Murphy TC, Rahnert J, Song H, Nanes MS, Greenfield EM, Jo $\mathrm{H}$ and Fan X: Mechanical inhibition of RANKL expression is regulated by H-Ras-GTPase. J Biol Chem 281: 1412-1418, 2006.

40. Sharma R, Wu X, Rhodes SD, Chen S, He Y, Yuan J, Li J, Yang X, Li X, Jiang L, et al: Hyperactive Ras/MAPK signaling is critical for tibial nonunion fracture in neurofibromin-deficient mice. Hum Mol Genet 22: 4818-4828, 2013.

41. Zauli G, Rimondi E, Corallini F, Fadda R, Capitani S and Secchiero P: MDM2 antagonist Nutlin-3 suppresses the proliferation and differentiation of human pre-osteoclasts through a p53-dependent pathway. J Bone Miner Res 22: 1621-1630, 2007.

42. Wang X, Kua HY, Hu Y, Guo K, Zeng Q, Wu Q, Ng HH, Karsenty G, de Crombrugghe B, Yeh J, et al: p53 functions as a negative regulator of osteoblastogenesis, osteoblast-dependent osteoclastogenesis, and bone remodeling. J Cell Biol 172: $115-125,2006$.

43. Zambetti GP, Horwitz EM and Schipani E: Skeletons in the p53 tumor suppressor closet: genetic evidence that p53 blocks bone differentiation and development. J Cell Biol 172: 795-797, 2006

44. Zhang J, Lazarenko OP, Blackburn ML, Badger TM, Ronis MJ and Chen JR: Blueberry consumption prevents loss of collagen in bone matrix and inhibits senescence pathways in osteoblastic cells. Age (Dordr) 35: 807-820, 2013.

45. Li Y and Tollefsbol TO: p16(INK4a) suppression by glucose restriction contributes to human cellular lifespan extension through SIRT1-mediated epigenetic and genetic mechanisms. PLoS One 6: e17421, 2011.

46. Campisi J and d'Adda di Fagagna F: Cellular senescence: when bad things happen to good cells. Nat Rev Mol Cell Biol 8: 729-740, 2007.

47. Wang $\mathrm{X}$, Huang $\mathrm{H}$ and Young $\mathrm{KH}$ : The PTEN tumor suppressor gene and its role in lymphoma pathogenesis. Aging (Albany NY) 7: 1032-1049, 2015.

48. Zhang LY, Ho-Fun Lee V, Wong AM, Kwong DL, Zhu YH, Dong SS, Kong KL, Chen J, Tsao SW, Guan XY, et al: MicroRNA-144 promotes cell proliferation, migration and invasion in nasopharyngeal carcinoma through repression of PTEN. Carcinogenesis 34: 454-463, 2013.

49. Blüml S, Friedrich M, Lohmeyer T, Sahin E, Saferding V, Brunner J, Puchner A, Mandl P, Niederreiter B, Smolen JS, et al: Loss of phosphatase and tensin homolog (PTEN) in myeloid cells controls inflammatory bone destruction by regulating the osteoclastogenic potential of myeloid cells. Ann Rheum Dis 74 $227-233,2015$

50. Jang HD, Noh JY, Shin JH, Lin JJ and Lee SY: PTEN regulation by the Akt/GSK-3 $\beta$ axis during RANKL signaling. Bone 55: $126-131,2013$

51. Sugatani T, Alvarez U and Hruska KA: PTEN regulates RANKL- and osteopontin-stimulated signal transduction during osteoclast differentiation and cell motility. J Biol Chem 278: 5001-5008, 2003.

52. Hu G, Han C and Chen J: Inhibition of oncogene expression by green tea and (-)-epigallocatechin gallate in mice. Nutr Cancer 24: 203-209, 1995.

53. Prasad KN, Kumar A, Kochupillai V and Cole WC: High doses of multiple antioxidant vitamins: essential ingredients in improving the efficacy of standard cancer therapy. J Am Coll Nutr 18: 13-25, 1999.

54. Xie L, Jiang Y, Ouyang P, Chen J, Doan H, Herndon B, Sylvester JE, Zhang K, Molteni A, Reichle M, et al: Effects of dietary calorie restriction or exercise on the PI3K and Ras signaling pathways in the skin of mice. J Biol Chem 282: 28025-28035, 2007.

55. Huang L, Bi HC, Liu YH, Wang YT, Xue XP and Huang M CAR-mediated up-regulation of CYP3A4 expression in LS174T cells by Chinese herbal compounds. Drug Metab Pharmacokinet 26: 331-340, 2011.

56. Yeon JT, Kim KJ, Choi SW, Moon SH, Park YS, Ryu BJ, Oh J, Kim MS, Erkhembaatar M, Son YJ, et al: Anti-osteoclastogenic activity of praeruptorin A via inhibition of p38/Akt-c-Fos-NFATc1 signaling and PLC $\gamma$-independent $\mathrm{Ca}^{2+}$ oscillation. PLoS One 9 e88974, 2014.

57. Hasegawa S, Yonezawa T, Ahn JY, Cha BY, Teruya T, Takami M, Yagasaki K, Nagai K and Woo JT: Honokiol inhibits osteoclast differentiation and function in vitro. Biol Pharm Bull 33: $487-492,2010$
58. Li J, Shao X, Wu L, Feng T, Jin C, Fang M, Wu N and Yao H: Honokiol: an effective inhibitor of tumor necrosis factor- $\alpha$-induced up-regulation of inflammatory cytokine and chemokine production in human synovial fibroblasts. Acta Biochim Biophys Sin (Shanghai) 43: 380-386, 2011.

59. Hahm ER, Singh KB and Singh SV: c-Myc is a novel target of cell cycle arrest by honokiol in prostate cancer cells. Cell Cycle 15: 2309-2320, 2016.

60. Liu H, Zang C, Emde A, Planas-Silva MD, Rosche M, Kühnl A, Schulz CO, Elstner E, Possinger K and Eucker J: Anti-tumor effect of honokiol alone and in combination with other anti-cancer agents in breast cancer. Eur J Pharmacol 591: 43-51, 2008.

61. Zhang J, Lazarenko OP, Blackburn ML, Shankar K, Badger TM, Ronis MJ and Chen JR: Feeding blueberry diets in early life prevent senescence of osteoblasts and bone loss in ovariectomized adult female rats. PLoS One 6: e24486, 2011.

62. Liu W, Lu X, He G, Gao X, Li M, Wu J, Li Z, Wu J, Wang J and Luo C: Cytosolic protection against ultraviolet induced DNA damage by blueberry anthocyanins and anthocyanidins in hepatocarcinoma HepG2 cells. Biotechnol Lett 35: 491-498, 2013.

63. Vetterli L, Brun T, Giovannoni L, Bosco D and Maechler P. Resveratrol potentiates glucose-stimulated insulin secretion in INS-1E beta-cells and human islets through a SIRT1-dependent mechanism. J Biol Chem 286: 6049-6060, 2011.

64. Martí-Centelles R, Falomir E, Murga J, Carda M and Marco JA: Inhibitory effect of cytotoxic stilbenes related to resveratrol on the expression of the VEGF, hTERT and c-Myc genes. Eur J Med Chem 103: 488-496, 2015

65. Wang X, Wang D and Zhao Y: Effect and mechanism of resveratrol on the apoptosis of lung adenocarcinoma cell line A549. Cell Biochem Biophys 73: 527-531, 2015.

66. Lee SJ, Park K, Ha SD, Kim WJ and Moon SK: Gleditsia sinensis thorn extract inhibits human colon cancer cells: the role of ERK1/2, G2/M-phase cell cycle arrest and p53 expression. Phytother Res 24: 1870-1876, 2010.

67. Lee SJ, Ryu DH, Jang LC, Cho SC, Kim WJ and Moon SK: Suppressive effects of an ethanol extract of Gleditsia sinensis thorns on human SNU-5 gastric cancer cells. Oncol Rep 29: 1609-1616, 2013

68. Lu Y, Li CS and Dong Q: Chinese herb related molecules of cancer-cell-apoptosis: a minireview of progress between Kanglaite injection and related genes. J Exp Clin Cancer Res 27: $31,2008$.

69. Li B, Zhao J, Wang CZ, Searle J, He TC, Yuan CS and Du W: Ginsenoside $\mathrm{Rh} 2$ induces apoptosis and paraptosis-like cell death in colorectal cancer cells through activation of p53. Cancer Lett 301: 185-192, 2011.

70. Gali-Muhtasib H, Kuester D, Mawrin C, Bajbouj K, Diestel A, Ocker M, Habold C, Foltzer-Jourdainne C, Schoenfeld P, Peters B, et al: Thymoquinone triggers inactivation of the stress response pathway sensor CHEK1 and contributes to apoptosis in colorectal cancer cells. Cancer Res 68: 5609-5618, 2008.

71. Ichwan SJ, Al-Ani IM, Bilal HG, Suriyah WH, Taher M and Ikeda MA: Apoptotic activities of thymoquinone, an active ingredient of black seed (Nigella sativa), in cervical cancer cell lines. Chin J Physiol 57: 249-255, 2014.

72. Lee SJ, Kim HM, Cho YH, Park K, Kim EJ, Jung KH, Kim CH, Kim WJ and Moon SK: Aqueous extract of Magnolia officinalis mediates proliferative capacity, $\mathrm{p} 21 \mathrm{WAF} 1$ expression and TNF-alpha-induced NF-kappaB activity in human urinary bladder cancer 5637 cells; involvement of p38 MAP kinase. Oncol Rep 18: 729-736, 2007.

73. Dong LH, Wen JK, Miao SB, Jia Z, Hu HJ, Sun RH, Wu Y and Han M: Baicalin inhibits PDGF-BB-stimulated vascular smooth muscle cell proliferation through suppressing PDGFR $\beta$-ERK signaling and increase in p27 accumulation and prevents injury-induced neointimal hyperplasia. Cell Res 20: $1252-1262,2010$

74. Zhang L, Pu Z, Wang J, Zhang Z, Hu D and Wang J: Baicalin inhibits hypoxia-induced pulmonary artery smooth muscle cell proliferation via the AKT/HIF-1 $/$ /p27-associated pathway. Int J Mol Sci 15: 8153-8168, 2014.

75. Byambaragchaa M, Dela Cruz J, Kh A and Hwang SG: Anticancer potential of an ethanol extract of Saussurea involucrata against hepatic cancer cells in vitro. Asian Pac J Cancer Prev 15: 7527-7532, 2014.

76. Liu J, Shen M, Yue Z, Yang Z, Wang M, Li C, Xin C, Wang Y, Mei Q and Wang Z: Triptolide inhibits colon-rectal cancer cells proliferation by induction of G1 phase arrest through upregulation of p21. Phytomedicine 19: 756-762, 2012. 
77. Liu TE, Zhang L, Wang S, Chen $\mathrm{C}$ and Zheng J: Tripterygium glycosides induce premature ovarian failure in rats by promoting p53 phosphorylation and activating the serine/threonine kinase 11-p53-p21 signaling pathway. Exp Ther Med 10: 12-18, 2015.

78. Wong TF, Takeda T, Li B, Tsuiji K, Kitamura M, Kondo A and Yaegashi N: Curcumin disrupts uterine leiomyosarcoma cells through AKT-mTOR pathway inhibition. Gynecol Oncol 122: 141-148, 2011.

79. Yoshida H, Okumura N, Kitagishi Y, Nishimura Y and Matsuda S: Ethanol extract of Rosemary repressed PTEN expression in K562 culture cells. Int J Appl Biol Pharm Technol 2: 316-322, 2011

80. Wang X, He H, Lu Y, Ren W, Teng KY, Chiang CL, Yang Z, Yu B, Hsu S, Jacob ST, et al: Indole-3-carbinol inhibits tumorigenicity of hepatocellular carcinoma cells via suppression of microRNA-21 and upregulation of phosphatase and tensin homolog. Biochim Biophys Acta 1853: 244-253, 2015.

81. Royston KJ and Tollefsbol TO: The epigenetic impact of cruciferous vegetables on cancer prevention. Curr Pharmacol Rep 1: 46-51, 2015.

82. Eason RR, Velarde MC, Chatman L Jr, Till SR, Geng Y, Ferguson M, Badger TM and Simmen RC: Dietary exposure to whey proteins alters rat mammary gland proliferation, apoptosis, and gene expression during postnatal development. J Nutr 134: 3370-3377, 2004.

83. Ghosh-Choudhury T, Mandal CC, Woodruff K, St Clair P, Fernandes G, Choudhury GG and Ghosh-Choudhury N: Fish oil targets PTEN to regulate NFkappaB for downregulation of anti-apoptotic genes in breast tumor growth. Breast Cancer Res Treat 118: 213-228, 2009.
84. Ishii H, Horie Y, Ohshima S, Anezaki Y, Kinoshita N, Dohmen T, Kataoka E, Sato W, Goto T, Sasaki J, et al: Eicosapentaenoic acid ameliorates steatohepatitis and hepatocellular carcinoma in hepatocyte-specific Pten-deficient mice. J Hepatol 50: 562-571, 2009.

85. Rovito D, Giordano C, Vizza D, Plastina P, Barone I, Casaburi I, Lanzino M, De Amicis F, Sisci D, Mauro L, et al: Omega-3 PUFA ethanolamides DHEA and EPEA induce autophagy through PPAR $\gamma$ activation in MCF-7 breast cancer cells. J Cell Physiol 228: 1314-1322, 2013.

86. Kitagishi Y and Matsuda S: Diets involved in PPAR and PI3K/AKT/PTEN pathway may contribute to neuroprotection in a traumatic brain injury. Alzheimers Res Ther 5: 42, 2013.

87. Burdick AD, Bility MT, Girroir EE, Billin AN, Willson TM, Gonzalez FJ and Peters JM: Ligand activation of peroxisome proliferator-activated receptor-beta/delta(PPARbeta/delta) inhibits cell growth of human N/TERT-1 keratinocytes. Cell Signal 19: 1163-1171, 2007.

88. Mohapatra P, Satapathy SR, Siddharth S, Das D, Nayak A and Kundu CN: Resveratrol and curcumin synergistically induces apoptosis in cigarette smoke condensate transformed breast epithelial cells through a p21(Waf1/Cip1) mediated inhibition of Hh-Gli signaling. Int J Biochem Cell Biol 66: 75-84, 2015. 